\title{
El amor en el Antiguo Testamento: Hacia una cultura bíblica del amor
}

Marco Becerra Olaya (a)

Facultad de Teología Universidad Peruana Unión

Recibido: 20 mayo de 2017 Aceptado: 8 de junio de 2017

\section{La importancia de lo que creemos y pensamos}

No cabe duda que lo que un individuo o un grupo de personas piensan o creen es de suma importancia. Definitivamente, las creencias influyen en la actitud que se asume frente a la vida y en la forma en que alguien se relaciona con los demás. Las creencias definen a una comunidad y le imprimen una característica cultural especial. Se entiende como creencia el conjunto de ideas que los seres humanos aceptan como verdaderos y autoritativos. Dentro de estas ideas se encuentran los conocimientos y experiencias que una persona ha acumulado a lo largo de su vida, y que llegan a formar parte de su esquema mental.

Es más, las creencias son hasta normativas de los conceptos y actitudes morales no solo en el entorno social, sino también en la relación que se establece con Dios. En este sentido, pueden traer consecuencias satisfactorias o resultados trágicos en lo que atañe a la salvación. Un caso equivocado de esto último es lo que se creyó durante la Edad Media con respecto al carácter de la Divinidad cristiana. Por un lado, la iglesia había olvidado en gran parte la misericordia de Dios y le daba más importancia a sus juicios implacables. El mismo Jesucristo era presentado como un 
vengador despiadado e inmisericorde. Así, los hombres en esta época vivían constantemente temerosos de su furia repentina.

A puertas de concluir la Edad Media (siglo XVI), la gente aún era víctima de supersticiones y absurdas creencias sobre la vida y la muerte. Se anunciaba un cielo para los que hacían bien y un infierno en donde eran arrojados aquellos que no habían sido lo suficientemente buenos, creencia que era una mezcla de ideas religiosas y paganas. Además de esto, el pueblo creía que el mundo estaba lleno de demonios. Y para empeorar esta situación, la iglesia católica, sobre la base de su supuesta autoridad para perdonar los pecados, ${ }^{1}$ había establecido un sistema de indulgencias con el cual pretendía poner fin a tan desdichada realidad. Esta supuesta solución consistía en que la gente podía satisfacer las demandas de un Dios airado con determinadas obras y pagos específicos.

Bajo esta perspectiva, cualquiera podía comprar una indulgencia a través de la cual el perdón de sus pecados quedaba asegurado sin importar cuán graves hayan sido. Incluso, se les garantizaba la remisión de futuros delitos como en el caso de lo que el Papa Gregorio VIII declaró en 1187, a saber, que cualquiera que ayudase a financiar las cruzadas obtendría plena indulgencia. ${ }^{2}$ Lo que hace grave este hecho, es que se pensaba que este sistema de salvación estaba en concordancia con la doctrina de Cristo y los apóstoles y que, por ende, tenía su fundamento en las Sagradas Escrituras.

Fue precisamente por esta causa que un simple monje agustino (31 de octubre de 1517), pegara sus 95 tesis en la puerta de

${ }^{1}$ Karl-Heinz zur Mühlen, "Indulgence”, en Encyclopedia of Christianity, ed. Erwin Fahlbusch et al. (Grand Rapids, MI: Eerdmans, 2001), 2:695-96.

${ }^{2}$ Karl-Heinz zur Mühlen, "Indulgence”, 2:295. 
la Universidad de Wittenberg como un rechazo directo a semejante enseñanza. ${ }^{3}$ Estos hechos ilustran el poder que los pensamientos y las creencias tienen sobre el comportamiento. A todo esto, en la introducción de su libro Las creencias populares ¿Son bíblicas?, Samuele Bacchiocchi presenta dos razones principales por las cuales las creencias populares deben ser sometidas a escrutinio. Una de ellas es que los cristianos de mente abierta deben probar la validez de lo que creen sobre la base de la autoridad de la Biblia. ${ }^{4}$

\section{El amor: un concepto difícil de precisar}

En vista de la importancia de lo que se considera como válido o verdadero, en este artículo se intentará establecer una aproximación del significado del amor sobre la base de lo que la Biblia declara. Establecer un concepto claro del amor es algo que ha inquietado por largo tiempo a muchas personas. En este sentido, el intento por definir el amor ha concitado el interés de estudiosos en los diferentes campos del saber humano: filósofos, teólogos, antropólogos, abogados, sociólogos, psicólogos, terapeutas familiares, líderes religiosos, literatos, músicos, poetas, escritores, maestros, miembros de iglesia; etc. La lista es interminable. En los últimos años se han agregado a ella expertos en el campo de la bioquímica con lo cual se ha querido dar una explicación (muy buena, por cierto) de los procesos fisiológicos del amor. ${ }^{5}$

El autor de este artículo no pretende tener una respuesta definitiva, por cuanto lograr una definición precisa del amor repre-

${ }^{3}$ Teófanes Egido López, Las reformas protestantes (Madrid: Editorial Síntesis, 1992), 48-51.

${ }^{4}$ Samuele Bacchiocchi, Las creencias populares ¿Son bíblicas?, trad. Claudia Blath (Berrien Springs, MI: Biblical Perspectives, 2008), 8.

${ }^{5}$ Helen Fisher, Por qué amamos (Buenos Aires: Taurus, 2004), 69-95. 
senta una ardua tarea. Por esta razón, se presentarán algunas pautas que podrían empezar por ayudar a esclarecer algunas inquietudes en torno a lo que podría significar.

Durante años, se han escuchado exposiciones (mayormente sinceras y bien intencionadas) que han querido establecer una definición clara de lo que es el amor. La más común es aquella en la que se han presentado las clásicas posturas de los diferentes tipos de afecto como el ágape, el eros y el filos. Desde este punto de vista, se presenta al amor ágape como un amor altruista, espontáneo, incondicional, puro, que solamente da, pero que nunca recibe. Un amor inmotivado emocionalmente, que solo Dios es capaz de prodigar. ${ }^{6}$ En cambio el eros es un tipo de amor que desea, impulsivo, que adquiere, que es motivado por el interés personal y dura hasta que su deseo haya sido satisfecho. ${ }^{7}$ En el caso del amor filos, se lo concibe más como un afecto amical y fraternal; dirigido hacia los amigos y los parientes más cercanos como los padres y los hermanos.

También están los que piensan que tal vez ninguno de ellos es completamente malo ni completamente bueno, que todo depende del equilibro que haya entre ellos (en realidad, la discusión gira, mayormente, en torno al amor ágape y al amor eros.). ${ }^{8} \mathrm{Se}$ presenta al amor ágape como un amor nacido de la voluntad que le resta importancia a los sentimientos y a las expresiones físicas,

${ }^{6}$ Lo inaudito de este punto es que un amor ágape inmotivado emocionalmente implica la idea de un Dios con la terrible enfermedad de la antropopatía. Ver Donald A. Carson, La difícil doctrina del amor de Dios (Barcelona: Publicaciones Andamio, 2001), 33. Con respecto a la imposibilidad de un Dios impasible, ver Charles Hodge, Systematic Theology (Grand Rapids, MI: Christian Classics Ethereal Library, 2005), 1:428-429.

${ }^{7}$ John C. Peckham, The Love of God: A Canonical Model (Downers Grove, IL: Intervarsity Press Academic, 2015), 69-70.

${ }^{8}$ Uno de los trabajos más representativos de la idea del ágape y eros y que marcó una tendencia en la forma de concebir el amor cristiano fue el de Nygren. Ver Anders Nygren, Agape and Eros (Philadelphia: The Westminster Press, 1953). 
en suma: un amor fuera de la esfera sensorial. En cambio, el eros es una clase de amor que pone énfasis en los sentidos: sexual, instintivo y, en algunos casos, animal. No obstante, este grupo cree que mientras exista un equilibrio entre el ágape y el eros las cosas pueden marchar bien. Ni demasiado eros ni demasiado ágape. Todo en la justa medida: la receta perfecta. ¡No se ha visto algo más descabellado que esto! Lo que empeora aún más las cosas, es que la mayoría alega que estas enseñanzas se encuentran en las Sagradas Escrituras.

Esta clase de posturas crea confusión y genera toda clase de sentimientos de culpa, por cuanto el elemento sensorial (la capacidad de experimentar sensaciones y sentimientos de todo tipo, incluyendo el sexual) es parte integral del ser humano. Se empuja al que acepta semejante filosofía a dos extremos opuestos. Por un lado, a una experiencia reprimida, casi ascética, un puritanismo ridículo, algo parecido al idealismo de Platón (uno de los máximos exponentes de esta clase de amor) que ve con sospecha cualquier sensación en el campo físico. Por otro lado, conduce a una vida llena de frustraciones porque tal experiencia es imposible de lograr, de tal forma que algunos llegan a la conclusión que mejor sería dejar que sus impulsos se desborden sin control. Todo esto enmarcado dentro de una antropología dualista, es decir, aquella que plantea que el ser humano está conformado por dos elementos fundamentales y, a la larga, irreconciliables: un cuerpo temporal, malo y con tendencia a la degeneración; y un alma de origen divino, buena, eterna, atemporal y perfecta.

Esta comprensión se basa mayormente en el entendimiento del significado etimológico de estas palabras. Esta postura presenta la idea de que, atendiendo al significado primario de estos términos, se concluye inevitablemente que existen diferentes clases de amor, algunos más puros y buenos que otros.

En vista de que el propósito de este artículo apunta hacia la creación de una conciencia y una cultura bíblica del amor, se em- 
pezará por acudir a la fuente primaria del canon bíblico: el Antiguo Testamento (AT). ${ }^{9}$ A partir de esta analizaremos en base a una comprensión contextual y etimológica lo que el amor es en realidad.

\section{El amor en el Antiguo Testamento}

La razón principal por la cual se acude al AT como primera fuente es el hecho de que, cuando se quiere dar explicación acerca del origen de un pensamiento dado ya sea filosófico, religioso, etc., o sencillamente se quiere encontrar la causa última del origen de alguna de las características del pensamiento actual, lamentablemente se suele escarbar en los anales de la cultura greco-latina. Esto sucede porque que existe una corriente que considera a esta como la matriz original de la civilización moderna, incluyendo el cristianismo. ${ }^{10}$ En este punto, muchos estudiosos de las Escrituras se han desviado otorgándoles exagerada importancia a los clásicos griegos y latinos. En el caso de los conceptos dicotómicos de eros y ágape, ambos son catalogados por el autor de este trabajo como el producto de tal influencia. En este acápite se realizará un viaje a través del tiempo, mucho más atrás del surgimiento de estas dos culturas europeas y la atención se centrará en el Antiguo Cercano Oriente (ACO), específicamente en los tiempos del AT.

El AT se escribió casi enteramente en idioma hebreo. Esta lengua es una de las tantas que provienen del tronco semita y es algo parecida, en este sentido, al español, el portugués, el francés o el italiano, las cuales provienen de un tronco común: el latín.

${ }^{9}$ Es importante precisar que el término ágape es una traducción directa del término hebreo para amor. Esto se ve claramente reflejado, en primera instancia, en la Septuaginta (Traducción griega del AT). Posteriormente, el término es usado por los escritores del Nuevo Testamento.

${ }^{10}$ Jaime Pastor Verdú, Eurocentrismo, Europeísmo y Eurofobia (Universidad Nacional Autónoma de México), 2. http://conceptos.sociales.unam.mx/conceptos_final/510trabajo.pdf 
Desde este ángulo, el idioma hebreo es muy parecido al español. Por lo tanto, cada vez que se estudia un término, siempre se tiene en cuenta la asociación que podría tener con aquellas lenguas con las cuales tiene mucha familiaridad, tales como el árabe, el arameo, el cananeo o el ugarítico.

Un ejemplo que podría ilustrar tal asociación en el estudio del origen y el significado de las palabras es el conocido término español de origen griego ${ }^{11}$ filosofía. Comúnmente, se quiere comprender el campo de estudio de esta ciencia teniendo en cuenta su raíz etimológica: de la voz griega filos, que significa amor; y sofía, que significa sabiduría. Es decir, que la filosofía es la ciencia que trata del estudio del amor a la sabiduría. Este concepto es muy simplista, por cuanto en la actualidad el campo de acción de esta disciplina es muy amplio y hasta confuso, y está por encima de la simple comprensión etimológica de la palabra. Sin embargo, nadie discute que el término español filosofía sea de origen griego.

\section{La propuesta etimológica}

En el caso del término amor en el AT, este es presentado mayormente como un verbo y muy pocas veces como un sustantivo. Tal vez porque el amor esté ligado originalmente a un acto. En este punto, es importante precisar que el pensamiento hebreo

${ }^{11} \mathrm{El}$ griego no es un idioma de origen latín, pero su familiaridad con el español se debe a que comparten varios grafemas. Aparte de esto, existen en el castellano muchos términos de origen griego que han sido asimilados a dicha lengua. Esto es muy común en todos los idiomas, porque el fenómeno de fusión y los préstamos lingüísticos se han dado desde siempre en la historia de la evolución de las lenguas. Ver Jorge Bergua Cavero, Los helenismos del español (Madrid: Editorial Gredos, 2004), 21-30. 
le da mucho énfasis a la acción; ${ }^{12}$ tanto es así que en la construcción de sus estructuras sintácticas el verbo siempre va en primer lugar (por ejemplo: “y dijo Jehová a Moisés"), a diferencia del idioma español en donde se verifica que la oración empieza mayormente con un sustantivo (por ejemplo: "Juan ama a María"). Decimos esto porque este estudio está orientado a entender el concepto de amor en base a la calidad verbal (acción) del término hebreo en el AT.

Antes de proporcionar una breve información del significado etimológico del término amor en el AT, es necesario precisar el campo de estudio de esta disciplina. La etimología es la ciencia que estudia el origen, la estructura y el cambio de las palabras. ${ }^{13}$ Esto incluye el estudio del proceso evolutivo de los términos, el cual da como resultado, con el paso del tiempo, el surgimiento de una variada gama de vocablos que, aunque tienen la misma raíz, ostentan significados tan distintos que nadie sospecharía su procedencia común.

Con respecto a la etimología como herramienta léxica, Thiselton expresa que "las consideraciones etimológicas pueden

${ }^{12}$ Ferdinand O. Regalado, "Hebrew Thought: Its Implications for Christian Education", Journal of the Adventist Theological Society 12, no. 2 (2001): 101-102.

${ }^{13}$ Alejandra Arana Rodríguez, Etimologías grecolatinas: Práctica, ocios y teoría (México DF: Edere, 2011), 27. Por otro lado, Zamboni expresa que "se admite comúnmente que la etimología es la ciencia que estudia el origen de las palabras o, en otros términos, la investigación de las relaciones formales y semánticas que ligan una palabra con otra unidad que la precede históricamente y de la que se deriva. Dicho esto, son necesarias algunas precisiones importantes: en primer lugar, la investigación del origen (mediato o inmediato) implica, en cuanto tal, una actitud que trata de explicar la naturaleza de las cosas a través de una interpretación del lenguaje, adhiriéndose directamente al pensamiento de los griegos, que concibieron la etimología precisamente como conocimiento del 'verdadero' (étymos) sentido de las palabras". Ver Alberto Zamboni, La etimología (Madrid: Editorial Gredos, 1988), 9-10. 
ocasionalmente ser de valor, como; por ejemplo, en los casos de homonimia, cuando dos palabras distintas de significados diferentes, tienen la misma forma léxica. Pero en el caso del estudio de la Biblia, no es seguro restringir el significado del Mensaje Inspirado al estudio de la etimología". ${ }^{14}$ Sin embargo, a manera de descarte, se probará por este lado solo para que el lector pueda estar seguro.

Etimológicamente, la raíz de $a h a b$ ('amar') y sus derivados como ahabah ('amor'), oheb ('amigo, alianza') y ahabim ('amores') aparecen no solo en el AT y los textos de la literatura hebrea en general, sino que también se pueden verificar en los dialectos semíticos. ${ }^{15}$ Como suele suceder en las etimologías, esta raíz ha estado en constante cambio de tal forma que su significado ha variado mucho dependiendo de las circunstancias. ${ }^{16}$

Estadísticamente hablando, de las 251 veces que la raíz aparece en el AT, 231 corresponden al modo qal (incluidas las 65 veces para oheb, las 53 veces para ahabah, 1 vez para nifal, 16 veces en piel, 2 veces para ahabim y 1 vez para ohabim). El empleo más frecuente del verbo se da en los Salmos (4 veces), Proverbios (23 veces), Oseas (19 veces), Cantares (18 veces) y Génesis (15 veces). Los casos del modo piel se encuentran distribuidos entre Jeremías, Ezequiel y Oseas. Los casos de oheb son más frecuentes en los Salmos y Proverbios (17 veces en cada uno); y

${ }^{14}$ Anthony Thiselton, "Semantics and New Testament Interpretation", en New Testament Interpretation: Essays on Principles and Methods, ed. I. Howard Marshall (Grand Rapids, MI: Eerdmans, 1977), 81.

${ }^{15}$ Wallis, "bha", en Theological Dictionary of the Old Testament, eds. G. J. Botterweck y H. Ringren (Grand Rapids, MI: Eerdmans, 1974), 1:101. En adelante TDOT. Ver también P. J. J. S. Els, "bha”, en New International Dictionary of the Old Testament Theology and Exegesis, ed. Willem A. VanGemeren (Grand Rapids, MI: Zondervan Publishing House, 1997), 1:277278. En adelante NIDOTTE.

${ }^{16}$ Ibíd. 
los de ahabah, ('amor') en Cantares (11 veces, incluyendo Cantares 3:10) y en Deuteronomio (9 veces). ${ }^{17}$

E. Jenni declara que $a h a b$ coincide fundamentalmente con el verbo español amar en la extensión del significado y que, junto con otros verbos que denotan sentimientos como hps ('hallar gusto'), yr' ('temor') y sn' ('odiar'), pertenece a los pocos verbos que tienen flexión estativa con sentido transitivo. ${ }^{18}$ Una explicación que es necesaria hacer es que los verbos estativos son una clase formal que en lugar de describir una acción, describen un estado del sujeto. Por ejemplo: "Pedro está enamorado".

En el caso de los verbos transitivos, estos son aquellos que ejercen una acción directa sobre una persona o cosa (objeto directo) que se encuentra en el predicado de una oración. Por ejemplo: "Juan ama a María". No obstante, si combinamos el carácter estativo/transitivo de $a$ hab tendríamos el siguiente ejemplo: "Juan ama (está enamorado de) a María". Por tanto, se deduce que Juan se encuentra en un estado emocional de enamoramiento, pero ese estado se transforma en una acción cuando es dirigida hacia un objeto: María. En este sentido, el estado se encuentra combinado con la acción. Tal es la característica especial del verbo $a h a b$ en hebreo, el cual no solamente describe una acción, sino también un estado interno del sujeto que realiza la acción de amar.

Al inicio de esta sección, se dijo que la raíz de la palabra amor en el AT es presentada como un verbo, de modo que el significado básico de la palabra denota acción. El término "amor", equivalente al sustantivo ahabah, no es el significado básico. Este

${ }^{17}$ E. Jenni, Diccionario Teológico Manual del Antiguo Testamento (Madrid: Ediciones Cristiandad, 1978), 1:116-117. El estudio de Wallis presenta la siguiente estadística: como verbo, $a h a b$ aparece 193 veces; y como sustantivo, ahabah ocurre 54 veces. Ver TDOT, 1:102

${ }^{18}$ Jenni, 1:117. 
sustantivo apenas es un derivado de la palabra $a h a b^{19}$ (amar). Esto nos lleva a considerar lo siguiente: “Que la clasificación funcional del verbo $a h a b$ se hace sobre la base de los tipos de personas o cosas que aparecen como objetos de una determinada acción: amor entre hombre y mujer, las demás relaciones personales, relaciones con objetos en las que también pueden entrar declaraciones más generales como el sustantivo ahabah". ${ }^{20}$

La referencia semántica primaria de $a h a b$ no es personal (sust. ahabah), dado que es un verbo que denota estado o acción. En el caso de eros, filia y ágape, parece que sí hay una connotación sustantiva; sin embargo, al trasladarse la palabra $a h a b$ al griego, lo hizo con el significado básico ('amar') hebreo. ${ }^{21}$ Desde este punto de vista, el significado primario de ahab ('amar') no está relacionado con un nombre (sust. ahabah = 'amor'), de ahí que se haga referencia a su cualidad verbal que, como se dijo antes, denota estado o acción. ${ }^{22}$

Con esto en mente, es que se procurará un estudio etimológico más extendido de la palabra $a h a b$. Sin embargo, a manera de advertencia para aquellos que deseen establecer una enseñanza

${ }^{19}$ De acuerdo a su origen y derivación, los sustantivos hebreos pueden ser divididos en tres clases: (1) Los sustantivos primitivos. Son aquellos cuyo origen se desconoce. El número de tales sustantivos es muy pequeño en el AT. (2) Los sustantivos de origen verbal. La vasta mayoría de los sustantivos hebreos, derivan de los verbos. Aquí está incluido el sustantivo ahabah ('amor'), el cual es un derivado del verbo ahab ('amar'). Finalmente, (3) los sustantivos hebreos que derivan de otros sustantivos. Un ejemplo claro de esto es la palabra principio de Génesis 1:1, la cual deriva del sustantivo cabeza. Ver Page H. Kelley, Biblical Hebrew: An Introductory Grammar (Grand Rapids, MI: Eerdmans, 1992), 36. Ver también Bruce K. Waltke y M. O'Connor, Biblical Hebrew Syntax (Winona Lake, Indiana: Eisenbrauns, 1990), 83-85.

\footnotetext{
${ }^{20}$ Ibíd.

${ }^{21}$ Ibíd.

${ }^{22}$ Jenni, 1:117.
} 
bíblica a partir de la etimología de los términos, la raíz de la palabra $a h a b$ es incierta. ${ }^{23}$

No obstante, algunos estudiosos han intentado establecer el significado primario de la palabra ahab ('amor') a partir de un estudio etimológico de la raíz en relación al parentesco que el hebreo tiene con algunos idiomas del ACO. En primer lugar, se encuentra el término egipcio ' $h-i$ ',- $b w$, que se traduce simplemente como 'amor'. ${ }^{24}$ Jenni y Westermann afirman que $a$ hab proviene de una raíz onomatopéyica ${ }^{25}$ biliteral ' $h b$ : 'soplar, respirar profundamente, exigir'. ${ }^{26}$ Por otro lado, Schultens, Winsche y Schwally sostienen que este verbo se relaciona a raíces semejantes como s' $p, n h m, n s m$, etc., los cuales unen la idea de 'respiro' con la de 'emotividad'.

Luego se encuentra el término árabe بَás ('dio'); el árabe $h b b$, que significa "ocultamiento protector", el cual a su vez es

${ }^{23}$ Wallis, "ahab", en TDOT, 1:102. Thomas sostiene que la corriente léxica es inadecuada para establecer un significado claro del término amor (אהב), puesto que la información para tal efecto es insuficiente y las propuestas son variadas y diversas. Ver D. Winton Thomas, "The Root אהב 'Love' in Hebrew", Zeitschrift fu " $r$ die alttestamentliche Wissenschaft, no. 1-2 (1939): 57-58. En adelante $Z A W$. Thomas añade la idea de que no se puede hacer exégesis de esta etimología. Ver ZAW, 64.

${ }^{24}$ Vine sostienen que, en su forma verbal, $a$ hab se refiere al amor que siente un hombre por una mujer y viceversa. Dicho amor se basa en el deseo "sexual" que generalmente se mantiene dentro de las relaciones lícitas: "y la trajo Isaac a la tienda de su madre Sara, y tomó a Rebeca por su mujer y la amó" (Gn 24:67). Ver Merrill F Unger y William White, Diccionario expositivo de palabras del Antiguo y del Nuevo Testamento exhaustivo (Nashville, TN: Editorial Caribe, 2001), 16.

${ }^{25}$ Se entiende por onomatopeya aquella representación gráfica de los sonidos de la naturaleza.

${ }^{26}$ Thomas también está de acuerdo con que el origen de $a h a b$ sea la raíz onomatopéyica ' $h b$, que para él se traduciría como 'soplar y soplar'. Ver $Z A W$, 57. 
conectado con el término hebreo 'b (אב), que significa "seno". También se encuentra el término" "ywn (אאיון): "escondite". 27 Luego están las etimologías "asado" en sinónimo con la etimología "quemado con amor" e "inclinado a". ${ }^{28}$ Una de las teorías más significativas es la que considera el árabe $h a b b a,{ }^{29}$ que significa "soplar mucho, soplar fuerte o estar excitado". 30 Para defenderla se citan algunos textos tales como Proverbios 30:15; Salmos 55:23 y Oseas 8:13.

Hirschberg está de acuerdo con la opinión anterior cuando dice que, aunque la raíz $a h a b$ es dudosa, está usualmente conectada con el término árabe en cuestión: "estar excitado". Este erudito añade que "dos raíces semíticas más combinan el concepto de $a h a b$ con 'conocimiento carnal' y 'piel' del hebreo $b a$ sar, mientras que en el árabe basar es también un término para "pene"" 31 Asimismo, el árabe basara significa "acostarse con", "cohabitar". Una analogía es ofrecida por la palabra hebrea nld, la cual aparece solo una vez en Job 16:15 significando "piel". El árabe jild significa lo mismo, pero puede ser comparado con jald "pene", y con jalada "desflorar", "violar", "violación".32 Todo esto indica que la raíz $a h a b$ ha sufrido, inevitablemente, una marcada evolución.

Suponiendo que estas explicaciones fueran plausibles, se harían problemáticos textos como: "Jehová se manifestó a mí

${ }^{27}$ ZAW, 59-60.

${ }^{28}$ Ibíd, 61.

${ }^{29}$ Este idioma también pertenece al tronco semita y, por lo tanto, tiene un marcado parentesco con el idioma hebreo. Al parentesco que existe entre un idioma y otro se le conoce con el nombre de cognado.

${ }^{30}$ TDOT, 2:102. Esta postura es muy parecida a la Jenni y Westermann, además de la de Thomas.

${ }^{31}$ Harris H. Hirschberg, "Some Additional Arabic Etymologies in Old Testament Lexicography", Vetus Testamentum 11 (1961): 373. En adelante $V T$.

${ }^{32}$ Hirschberg, VT, 374. 
hace ya mucho tiempo, diciendo: Con amor eterno te he amado; por tanto, te prolongué mi misericordia" (Jer 31:3). En el caso de que aplicásemos la etimología "estar excitado" el versículo tendría el siguiente sentido: "Jehová se manifestó a mí hace ya mucho tiempo, diciendo: Con excitación eterna te he amado; por tanto, te prolongué mi misericordia". Algo similar sucedería con este otro versículo: "Porque de tal manera amó Dios al mundo, que ha dado a su hijo unigénito, para que todo aquel que en él cree, no se pierda, mas tenga vida eterna" (Jn 3:16). Nadie en su sano juicio aceptaría que Jesús murió por la raza humana porque Dios experimentó un "fuerte respiro o excitación" hacia ella. En el caso de las otras etimologías, no son necesarios más ejemplos.

En el otro lado está la idea que asocia la raíz de la palabra $a h a b$ con el árabe ihab: "piel (humana)", "cuero" o "guarnición de cuero" (basado en Cantares 3:10). Dicha asociación se hace con el supuesto de que el término hace alusión directa a una sensación en el terreno físico del ser y a la estimulación emocional que produce. ${ }^{33} \mathrm{Si}$ esta propuesta es correcta, entonces el origen y el desarrollo del concepto de $a h a b$ estaría relacionado con la experiencia emocional. ${ }^{34}$ Parece que esta última declaración se encuentra fundamentada por el hecho de que el aspecto emocional del amor aparece en contraste con sentimientos opuestos como el odio como en Deuteronomio 5:9, 10; 21:15; Jueces 14:16; $2 \mathrm{~S}$ 19:7 (6); Isaías $61: 8$, etc. ${ }^{35}$

${ }^{33}$ G. R. Driver, "Supposed Arabisms in the Old Testament", Journal of Biblical Literature, no. 55 (1936): 111.

${ }^{34}$ Ibíd.

${ }^{35}$ TDOT, 1:02. Quell y Stauffer están de acuerdo con esta idea cuando afirman que la declaración que concibe el amor como una experiencia de índole emocional está apoyada, al menos, por el hecho de que en el AT se lo presenta en contraste con sentimientos como el odio (Dt 5:9, 10; 21:15). Ver

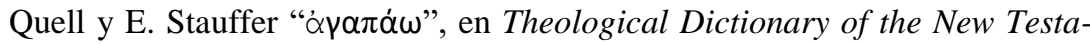
ment, eds. G. Kittel y G. Friedrich (Grand Rapids, MI: Eerdmans, 1964-1976), 
Hasta el momento se ha visto que no existe nada especial en el significado etimológico de la palabra. Tampoco existe alusión a alguna forma particular de amar, tal como sostienen los que priorizan la idea de un amor especial escondido en el término mismo propuesto en la filosofía del amor ágape y eros. Se afirma esto porque el término griego ágape, es una traducción directa del término hebreo $a h a b$. Por lo tanto, debería haber en este último algún significado que se asemeje a la idea de un amor puro y divino.

El estudio de la raíz etimológica de los términos bíblicos puede resultar muy traicionero en el sentido de que no ayuda a establecer la validez de las enseñanzas cristianas. Para ilustrar lo que se viene diciendo, es muy útil uno de los ejemplos de Anthony Thiselton, reconocido experto en hermenéutica bíblica. Él utiliza la palabra inglesa nice ("agradable" o "bonito" en español). Este término proviene de la voz latina nescius y etimológicamente significa 'ignorante' ${ }^{36}$ Ahora bien, supongamos que alguien se dirija a su esposa y le diga: "you are a nice woman" ('tú eres una mujer bonita'). nadie pondría en tela de juicio el sentido positivo de lo que le está diciendo basado en el significado original de la palabra, que, aunque etimológicamente signifique "ignorante", sin embargo, en el uso corriente, significa precisamente eso: "bonito, agradable". Otros podrían decir, que como "nice" proviene de nescius, entonces podría haber una relación entre ser bonito e ignorante, por cuanto muchos han satanizado la belleza, relacionándola con la frivolidad y lo superfluo y que en este caso lo que es bonito es negativo. Porque creen que la belleza de carácter es incompatible con la belleza física: ipuro dualismo!

1:21-25. En adelante TDNT. Sin embargo, el elemento emocional no es el único que está presente en la experiencia de amar.

${ }^{36}$ Ibíd. 
Entonces, ¿se está diciendo con esto que la etimología como herramienta de estudio de las palabras no sirva?, ¡de ninguna manera! Con respecto a esto, Carson afirma que cuando se trata de hacer un estudio del significado diacrónico ${ }^{37}$ de la palabra a través de largos períodos de tiempo es completamente útil, pues al tratar de buscar el significado más antiguo se puede lograr, de forma inductiva en base a los cognados ${ }^{38}$ con otras lenguas similares, una comprensión más amplia. ${ }^{39}$

Teniendo en cuenta la dificultad que se tiene para establecer un significado claro del amor sobre la base de la comprensión de la etimología del verbo $a h a b$, se suma a este estudio el siguiente elemento: el contexto bíblico. Desde este punto de vista, se encontrará que el término ahab y sus derivados tienen diversos usos ajenos al círculo etimológico. En el siguiente capítulo haremos mención de tales usos.

\section{El multifacético uso de $a h a b$}

El término $a h a b$ se usa para referirse a diferentes actos que van desde lo secular hasta lo religioso. Esto incluye la descripción de acciones buenas y malas. Desde este ángulo, no se debiera inferir que el término $a h a b$ y sus derivados indiquen alguna clase inherente de "divino significado". Es sorprendente ver cómo el término es usado para referirse tanto a cosas seculares como religiosas, su uso teológico podría sonar aún mucho más escandaloso

${ }^{37}$ Es la forma como las palabras han variado de forma y significado a través del tiempo.

${ }^{38}$ Se refiere al parentesco que tienen varias lenguas por provenir estas del mismo tronco lingüístico.

${ }^{39}$ D. A. Carson, Falacias exegéticas: Interpretación eficaz hoy (Barcelona: Editorial Clie, 2013), 39. 
para el pensamiento occidental. Pero este es un asunto que se desarrollará en acápites posteriores.

El término $a h a b$ describe acciones que incluyen el amor entre un hombre y una mujer. Por ejemplo: Isaac y Rebeca (Gn 24:67), Jacob y Raquel (Gn 29:18, 20, 30), el amor de un israelita hacia una pagana en el caso de Sansón y una mujer filistea (Jue 14:16), Sansón y Dalila (Jue 16:4, 15), el gozo sexual de una pareja de esposos jóvenes (Pr 5:18; cf. Ec 9:9), el amor de un pagano hacia una israelita en el caso de Siquem y Dina (Gn 34:3), ${ }^{40}$ y el amor enfermizo e incestuoso de Ammón hacia su hermana Tamar (2 S 13:1-19)..$^{41}$ Por otra parte, también se hace referencia a las relaciones conyugales mismas aunque se trate de una mujer fornicaria, adúltera o prostituta (Os 3:1-3). En el contexto de las relaciones familiares también designa la unión especial entre un padre y su hijo favorito (Gn 22:2; 25:28; 37:3; Pr 13:24), entre una madre y su hijo favorito (Gn $25: 28),{ }^{42}$ y entre una nuera y su suegra (Rt 4:15). Hasta se incluye la relación amistosa entre hombres, tal como la de Saúl y David (1 S 16:21), Jonathan y David (1 S 18:1-3), el maestro y su discípulo (Pr 9:8), el siervo y su amo (Éx 21:15), la relación íntima entre el pueblo y un líder militar (1 S 18:16, 22), el amor hacia los hombres y a los compatriotas ( $\mathrm{Lv}$ 19:18), y el amor hacia los extranjeros (Lv 19:34; Dt 10: 18,19).

El uso de $a h a b$ también incluye aspectos socio-éticos. De esta manera, describe lo inestable de la naturaleza humana: “tiempo de amar y tiempo de odiar" (Ec 3:8, cf. 9:1). Además, describe la disciplina y la reprensión como un acto de amor ( $\mathrm{Pr}$

${ }^{40} \mathrm{Al}$ parecer se trataba de un caso de abuso sexual. Ver Génesis 34:12, 4-7. Sea como fuere, estaba claro que era sexo fuera del matrimonio y en esto no hay nada de santo.

${ }^{41}$ Poner énfasis en los versículos $1,4,15$, pues en estos se usa el término $a h a b$.

${ }^{42}$ En este punto, el contexto indica un favoritismo de notables consecuencias negativas que harían de este amor una actitud poco recomendada. 
13:24; 9:8). Se declara que el hombre recto es amado (Pr 16:13). Se alude al amor de un amigo en tiempos de dificultad (Pr 17:17) y lo preferible del amor en contraste con la abundancia ( $\operatorname{Pr} 15: 17)$. Se habla del amor a la sabiduría como motivo de alegría paternal (Pr 29:3; 19:8), del amor hacia el próximo aun cuando este sea un enemigo (Lv 19:18), del amor hacia el extranjero (Lv 19:34), del amor hacia los que nos han hecho daño (1S 24:7; 26:11), etc. ${ }^{43}$

Los ejemplos anteriores utilizan indistintamente la raíz hebrea $a h a b$ para referirse a diferentes clases de actitudes hacia diferentes clases de individuos, con quienes se ha establecido diferentes formas de relación interpersonal. Esto nos lleva a concluir que el amor es eminentemente activo en el grado más alto que pueda existir. También nos hace pensar que el amor se traduce más como un conjunto de actitudes cuyo valor se desprende de lo que produce.

Norman Snaith opina que la raíz ahab es muy común en el idioma hebreo y que puede ser usada en toda clase de amor. Esta es una palabra perfectamente general y como tal está muy lejos de algún uso religioso exclusivo. ${ }^{44}$ Con respecto al uso religioso de la raíz, Snaith asegura que el verbo es usado 32 veces en relación al amor de Dios. De estas, dos describen el amor de Dios por Jerusalén (Sal 78:68), mientras que hay siete casos en los que Dios ama la justicia y el juicio. Existen también otros 23 casos de su amor por Israel e individuos particulares. Por otro lado, el verbo es usado 22 veces para denotar el amor del hombre hacia Dios; 19 veces para describir el amor al nombre de Dios, la ley, sus preceptos; etc., y 2 veces con referencia al amor del hombre por Jerusalén.

${ }^{43}$ En estos pasajes no se encuentra el término amor, pero el contexto implica un acto tal.

${ }^{44}$ Norman H. Snaith, The Distinctive Ideas of the Old Testament (London: The Epworth Press, 1957), 132. 
Para resumir, verificamos que la raíz es usada 27 veces en las que Dios aparece amando al hombre en contra de las 24 veces donde el hombre ama a Dios. Este último grupo incluye los cuatro casos del amor al nombre de Dios y el caso de Jeremías 2:2, pasaje que describe el amor de Jerusalén hacia Jehová. ${ }^{45}$

Algunos afirman que estas evidencias no son suficientes para establecer un concepto claro de amor porque sencillamente muestran un proceso de evolución sociocultural de tal virtud. Con respecto a esto, se presentará una paráfrasis de la opinión crítica de Wallis, quien pone de relieve que:

Las formas literarias relacionadas con los tipos de literatura que se encuentran en el AT característicamente han llenado la raíz $a h a b$ con contenido estereotipado y, por consiguiente, están interesadas en aspectos completamente diferentes del concepto de amor. Las fuentes narrativas están más interesadas en la relación de los hombres entre sí, mientras que los intereses didácticos y socio-éticos de la literatura sapiencial ven el mismo tema bajo símbolos que corresponden a este tipo de literatura. Los Salmos y el Cantar de Salomón, este último expresamente dedicado al tema del amor, son de un carácter diferente de los oráculos proféticos que critican las creencias y prácticas religiosas y sociales de los israelitas. ${ }^{46}$

En cuanto a los libros proféticos, Wallis sostiene que

Estos ponen mayor énfasis en el amor de Yahweh por su pueblo, en aquello que lo motivó a realizar actos poderosos para salvarlos, y en el fracaso de Israel en responder a este amor, hecho que se expresa en la figura de infidelidad y

\footnotetext{
${ }^{45}$ Ibíd, 132-133.

${ }^{46}$ Ibíd.
} 
desafección. Por último, el concepto de amor en los diversos tipos de literatura del AT se amplió y profundizó con el tiempo, especialmente al incluir el concepto del amor de Dios por el hombre y el amor del hombre por Dios. ${ }^{47}$

En realidad, lo que esta opinión está sugiriendo es que el amor es una simple construcción sociocultural. Y como tal es una expresión afectiva netamente humana. Esta opinión se hace con el supuesto de que los libros del AT no representan una unidad, sino que provienen de diferentes fuentes. A esto se le conoce como "crítica de las fuentes". ${ }^{48}$ Por ejemplo, Wallis dice que, en el principio, el concepto de amor no fue la base de los actos de Dios en medio de su pueblo o hacia algún individuo. Originalmente, fue el pacto el fundamento de tal unión. Únicamente después de que el pacto fuera sellado, recién quedaron unidos. Wallis continúa diciendo que, en el AT, la relación de Dios hacia un individuo no fue motivada por el $a h a b$. El hecho de que Dios haya rodeado con amor a los piadosos y a los justos, es evidentemente tardía, ${ }^{49} \sin$ embargo, cuando se lee Deuteronomio 7:7, $8^{50}$ queda

${ }^{47}$ Wallis, 1:104-105. Desde este punto de vista, se considera que los profetas sencillamente dieron cumplimiento a lo que estaba escrito en lo que algunos consideran como la "escuela deuteronomista" que, aparte de no aceptar que Moisés fuera el autor verdadero, sacaba el libro de Deuteronomio del Pentateuco y lo ponía en la misma categoría de Josué, Jueces, 1 y 2 de Samuel, y 1 y 2 de Reyes como escritos del siglo VII d.C. Sin embargo, los que creemos en la inspiración y la historicidad de las Escrituras aceptamos que Deuteronomio es parte de los libros que conforman el Pentateuco, los cuales se escribieron alrededor del siglo XV a. C. Para una mayor información sobre la escuela deuteronomista, ver José Luis Sicre, Introducción al Antiguo Testamento (Estella, Navarra: Editorial Verbo Divino, 2000), 75-90 y 136-180.

${ }^{48}$ Para comprender de qué trata la crítica de las fuentes, ver Gerhard Hasel, La interpretación de la Biblia (Buenos Aires: ACES, 1986), 9-20.

${ }^{49}$ TDOT, $1: 112$.

${ }^{50}$ Desde el punto de vista de la crítica de las fuentes el libro de Deuteronomio, y por ende el texto citado (Dt 7:7,8), fue escrito alrededor del siglo 
claro que el amor y el pacto estaban unidos, puesto que el término ahabah (de la raíz $a h a b$ ) describe la motivación por la que el Señor se fijó en Israel.

Una opinión parecida es la que plantea la escritora feminista Coral Herrera Gómez en su libro La construcción Sociocultural del amor romántico. En este trabajo, ella incide en la complejidad del amor como fenómeno sociocultural. El abordaje de su investigación parte del queer ${ }^{51}$ y su tesis central afirma que las emociones están medidas culturalmente y determinadas por los mitos, relatos, estereotipos y tabúes que las han devaluado durante siglos a la categoría de sentimientos irracionales no susceptibles de ser investigados con rigor académico. ${ }^{52}$

De ser válida esta presuposición, entonces estaríamos hablando del amor bíblico en términos de la evolución del pensamiento y las prácticas afectivas de la sociedad humana, lo cual nos llevaría a pensar en una moralidad y espiritualidad subjetiva y relativa a la época en la que se está viviendo. Por supuesto que en este trabajo se presupone que el amor debe y tiene que ser, en primera instancia, de origen divino. Una manifestación soberana de la voluntad de Dios, quien en todo momento se interesa por el bienestar total de sus criaturas. El elemento cultural no es ajeno a la experiencia de amar; sin embargo, el significado básico apunta

VII a.C. En este trabajo reconocemos la unidad del Pentateuco y como ya dijimos en uno de los pies de página anterior, fue escrito el siglo XV a.C.

${ }^{51}$ La palabra queer (literalmente significa 'raro') es un término que se utiliza para designar a quienes no son heterosexuales. En el contexto de la identidad política occidental, los individuos que se identifican como queer suelen buscar situarse aparte del discurso, la ideología y el estilo de vida que tipifican a las grandes corrientes en las comunidades LGBTI. Ver Carlos Fonseca Hernández y María Luisa Quintero Soto, "La teoría Queer: La de-construcción de las sexualidades periféricas", Sociológica, no. 69 (2009): 44-47.

${ }^{52}$ Coral Herrera Gómez, La construcción sociocultural del amor romántico, 2da ed. (Madrid: Editorial Fundamentos, 2010). Se recomienda leer todo el documento. 
a una acción cuyo valor se desprende de la motivación y los resultados que produce.

En este sentido, el uso del término ahab puede tener un sentido tanto religioso como secular. Se lo puede usar para referirse a la relación de amor de Dios hacia su pueblo y puede dirigirse tanto a una persona como a objetos.

\section{El significado teológico de $a h a b$}

Otro detalle importante que se debe resaltar es que el amor tiene un uso teológico muy marcado en el AT. Al margen de las exageradas etimologías y la evidencia de sus usos diversos, es innegable que el término $a h a b$ tiene también marcadas connotaciones sexuales. Desde este punto de vista, es usado por los profetas posteriores ${ }^{53}$ para describir la relación entre Yahweh y su pueblo bajo la figura del matrimonio. Algunos como Ziegler, creen que el concepto de pacto de Yahweh está fundamentado en la idea de una unión marital entre Jehová y su pueblo (Mal $2: 14){ }^{54}$

Este mismo término aparece cuando los hombres de Dios describen la infidelidad de Israel en términos de variadas formas de infidelidad sexual (Os 1-3; Ez 16:1-63). Se cree que esto solo es posible cuando se describen los pecados de Israel con las naciones vecinas; sin embargo, el elemento sexual figurado ilustra también el momento en que Dios decide escoger a su pueblo Israel a pesar de que, posteriormente, cual prostituta, se fuera en pos de sus amantes (Ez 16:23-26). Es en este momento en que Dios atrae con lazos de amor a su pueblo. El profeta describe esta

${ }^{53}$ Se les llama profetas posteriores a aquellos santos hombres que escribieron la porción del AT comprendida entre el libro de Isaías hasta Malaquías. Claro está que este espacio incluye tanto a los profetas mayores como a los profetas menores.

${ }^{54}$ Ziegler, 73-77. 
unión en términos simbólicos de una unión sexual: "Y pasé otra vez junto a ti, y te miré, y he aquí que tu tiempo era tiempo de amores; y extendí mi manto sobre ti, y cubrí tu desnudez; y te di juramento y entré en pacto contigo, dice el Señor Jehová y fuiste mía" (Ez 16:8). Aunque la raíz para la expresión "amores" no es $a h a b$, el término hebreo usado es el sustantivo dod, que tiene las connotaciones de "amado", “querido", “¡amor!", vocabulario que es muy frecuente en el Cantar de los cantares (cf. Cnt 8:14; $5: 16){ }^{55}$

Es claro que esto puede sonar muy escandaloso para la mentalidad occidental. En el mundo del AT, las relaciones sexuales eran vistas como algo muy natural. La única vez en que se ve el sexo de forma escandalosa es cuando se lo vincula a actos ilegales del mismo en términos de fornicación, adulterio, homosexualismo; etc. Tal vez no se entienda la verdadera dimensión de la sexualidad y el matrimonio, pero se sospecha que debe ser de suma importancia, por cuanto el Texto Inspirado no encontró una forma más adecuada para describir la unión de Dios con su pueblo, sino a través de la unión marital.

\section{La presencia implícita del amor de Dios}

En este punto, se resalta el hecho de que, al margen de los diferentes usos del término $a h a b$ y sus derivados en el AT, los actos de amor en las Escrituras aparecen aun cuando la raíz ahab no esté presente. Desde esta perspectiva, se afirma que, así como el estudio etimológico no es necesario para tener una comprensión real del concepto de amor en la Biblia ni mucho menos para determinar la diferencia entre los distintos tipos de amor, la presencia del término $a h a b$ no es obligatoria para afirmar que en tal o cual pasaje bíblico se pueden notar sus huellas o no.

${ }^{55}$ Luis Alonso Schökel, Diccionario bíblico hebreo-español (Madrid: Editorial Trotta, 2008), 173. 
Por lo tanto, la presencia de los actos de amor en las Escrituras, no dependen, en su totalidad, del uso de un término determinado. Donald Carson, al hablar de las diferentes formas en que la Biblia se refiere al amor de Dios, deja claro que no es necesaria la mención de la palabra amor. ${ }^{56}$ De hecho, él menciona cinco formas diferentes en que la Biblia habla del amor de Dios: ${ }^{57}$

(1) El amor especial del Padre hacia el Hijo (Jn 3:35; 5:20; 14:31).

(2) El amor proveedor de Dios hacia todo lo que ha creado (Gn 1 y $2 ;$ Mt 6:26; 10:29).

(3) La postura salvífica de Dios hacia el mundo caído (Jn 3:16; 1 Jn 2:2; Jn 15:19; Ez 33:11).

(4) El amor especial, eficaz y exclusivo hacia sus elegidos (Dt 7:7-8; 4:37; 10:14-15; Mal 11:2-3; Ef 5:25).

(5) Por último, a veces se dice que el amor de Dios va dirigido hacia su pueblo de forma provisional o condicional, es decir, está condicionado a la obediencia (Jud 21; Jn 15:9-10; Éx 20:6; Sal 103:8; 103:9-11, 13, 17-18).

Sin embargo, Carson advierte que ninguna de estas formas bíblicas de hablar del amor de Dios se absolutiza o exclusiviza; por eso, tampoco se deben convertir en el aspecto principal por el cual se relativizan las otras formas de amor de Dios. Tampoco debemos considerar estos diferentes aspectos del amor de Dios independientes y compartimentalizados. No nos ayudará el comenzar a hablar del amor que Dios nos provee, de su amor a los elegidos, de su amor dentro de la Trinidad, etc., como si cada uno de ellos estuviera cerrado herméticamente y separado de los demás. ${ }^{58}$

\footnotetext{
${ }^{56}$ La difícil doctrina del amor de Dios, 17.

${ }^{57}$ Ibíd., 17-22.

${ }^{58}$ Ibíd., 25
} 
Desde el ángulo de estos cinco puntos, Carson continúa diciendo que ninguno se debiera dejar llevar por clichés evangélicos que nada tienen que ver con lo que la Biblia enseña en cuanto el amor de Dios, tales como: 1) "el amor de Dios es incondicional" y 2) "Dios ama a todos exactamente igual". ${ }^{59}$ En este sentido, Dios tiene a sus elegidos, pero no esta elección no es arbitraria. Tampoco tiene que ver con mérito alguno. En el caso de la elección del pueblo de Israel, Dios deja muy claro que la motivación para tal acto fue simplemente producida por el amor. ${ }^{60}$

El autor de este artículo considera que los actos de amor más grandes y sublimes que se encuentran en las Sagradas Escrituras son la creación y la redención. Estos hechos son una demostración indiscutible. En cuanto al primer caso, Dios mismo declara que "todo era bueno en gran manera" (Gn 1:31). El segundo, esta expresado por el conocido texto juanino: "Porque de tal manera amó Dios al mundo, que ha dado a su Hijo unigénito, para que todo aquel que en él cree, no se pierda, mas tenga vida eterna" (Jn 3:16). Curiosamente, ambos incluyen a la humanidad entera.

En este último título, se ha hablado de la presencia implícita del amor de Dios a través de sus actos entre sus criaturas. Igualmente, existen hechos realizados por el ser humano mismo que indican amor sobreentendido. Tal es el caso de David cuando tiene la oportunidad de darle muerte a Saúl, pero no lo hace (1 S 24:4-22). O el caso de Booz, cuando este trató

${ }^{59}$ Ibíd., 25-26.

60،"Porque tú eres pueblo santo para Jehová tu Dios; Jehová tu Dios te ha escogido para serle un pueblo especial, más que todos los pueblos que están sobre la tierra. No por ser vosotros más que todos los pueblos os ha querido Jehová y os ha escogido, pues vosotros erais el más insignificante de todos los pueblos; sino por cuanto Jehová os amó, y quiso guardar el juramento que juró a vuestros padres, os ha sacado Jehová con mano poderosa, y os ha rescatado de servidumbre, de la mano de Faraón rey de Egipto" (Dt 7:6-8). Énfasis añadido. 
misericordiosamente a Rut, facilitándole las cosas (Rt 2:5-14). Es probable que Booz ya estaba prendado (enamorado) de ella cuando decidió ser generoso con la joven moabita. Incluso, Rut misma expresó amor sobreentendido cuando decidió quedarse con su anciana suegra. No existe en ningún momento la mención de la palabra amor durante el episodio en que tanto ella como su concuñada tuvieron que tomar una decisión, pero el contexto indica que un afecto muy especial la unía con Noemí por lo que decidió correr la misma suerte (Rt 1:16-18).

\section{Conclusión}

Entonces, en base a las evidencias presentadas, ¿es posible elaborar un concepto, por lo menos tentativo, de lo que es el amor? En uno de los párrafos anteriores habíamos dicho que el término $a h a b$ aparece mayormente como un verbo; por lo tanto, es posible definirlo más como una acción. Se había mencionado también que las razones etimológicas no son suficientes para definir una enseñanza bíblica, por cuanto su uso podría resultar falaz. Además, se han verificado los usos indistintos e intercambiables de la raíz ahab, cuyas aplicaciones iban desde la descripción de episodios profundamente negativos hasta el uso positivo más sublime. Por consiguiente, las razones que se han presentado apuntan a una comprensión contextual y hasta circunstancial.

También se mencionó que, al margen del elemento cultural, el significado básico debería entenderse como una acción cuyo valor se desprende de la motivación y los resultados que produce. Un detalle importante es que las acciones de $a h a b$ no están desprovistas del elemento emocional. Desde este punto de vista, no se parece en nada a la idea del cristianismo moderno de un amor más racional desprovisto de tal elemento.

Finalmente, la hora de la elaboración de un concepto ha llegado, pero antes es necesario advertir que la Biblia refleja un pensamiento que es necesario tener en cuenta: La elaboración de un 
concepto a partir de las Sagradas Escrituras está muy lejos de la abstracción occidental muy influida por el pensamiento griego. ${ }^{61}$ El pensamiento bíblico, al que podíamos designar también pensamiento hebreo, tiende por naturaleza hacia la concreción, es decir, sus conceptos giran en torno a una realidad palpable por los sentidos: a una acción. Desde este punto de vista, se conceptúa el amor más como un acto que podría tener motivaciones negativas o positivas, cuyo valor se desprende por los resultados que produce.

${ }^{61}$ Thorleif Boman, Hebrew Thought Compared With Greek (New York: W. W. Norton and Company, 1970), 27-73. 